\title{
Diffuse Alveolar Hemorrhage Associated with Proteinase 3-Specific Anti-Neutrophil Cytoplasmic Antibodies
}

\author{
Masayuki KiKawada, Yuichi Ichinose, Kazushige Minemura, Akira Kunisawa, \\ Hiroshi Kusumoto, Seiichi Okabe, Makoto Yonemaru, Makoto Ogura*, \\ Toshiyuki NAKaO*, Yoshiro EBriHara** and Keisuke TOYAMA
}

\begin{abstract}
A 31-year-old man was referred to our hospital for the management of progressive diffuse alveolar hemorrhage associated with renal dysfunction. Leukocytoclastic vasculitis was shown by skin biopsy and crescentic glomerulonephritis was also detected, in addition to positivity for proteinase 3-specific anti-neutrophil cytoplasmic antibodies (PR3-ANCA). The patient was diagnosed as a rare case of PR3-ANCA-positive pulmonary-renal vasculitic syndrome without granulomatous lesions. There was a good response to combination therapy with steroids and cyclophosphamide.
\end{abstract}

(Internal Medicine 36: 430-434, 1997)

Key words: alveolar hemorrhage, crescentic glomerulonephritis, anti-neutrophil cytoplasmic antibodies, Wegener's granulomatosis, microscopic polyangiitis

\section{Introduction}

When diffuse alveolar hemorrhage occurs in association with renal dysfunction, the well-known causes are Goodpasture's syndrome, systemic lupus erythematosus, and immune complex disease (1-3). Recently, it is considered that the most common cause of alveolar hemorrhagic syndrome is microscopic polyarteritis associated with anti-neutrophil cytoplasmic antibodies (ANCA) (4).

ANCA can be divided into two subsets by indirect immunofluorescent microscopy (5): one displays a cytoplasmic staining pattern (c-ANCA) and the other displays a perinuclear pattern (p-ANCA). The major target antigen of p-ANCA is myeloperoxidase (MPO-ANCA), while other antigens include neutrophil granule-associated elastase, lactoferin, and undefined nuclear antigens. The major target antigen of c-ANCA is a $29 \mathrm{kD}$ serine proteinase known as proteinase 3 (PR3-ANCA) (6). The presence of PR3-ANCA in a patient with pulmonaryrenal vasculitic syndrome is suggestive of WG or microscopic polyarteritis. We report a male patient with PR3-ANCA-positive vasculitis who presented with diffuse alveolar hemorrhage, crescentic glomerulonephritis, and other abnormalities.

\section{Case Report}

A 31-year-old man developed cough, low-grade fever, and arthralgia on February 5, 1996. He was treated with antibiotics and acetylsalicilic acid for these symptoms at a local hospital. Seven days later, he noticed hemoptysis and congestion of the bilateral bulbar conjunctivae. A chest X-ray film showed alveolar infiltrates in the right lung field. He was diagnosed as having pneumonia and was admitted to hospital on February 13. Despite antibiotic therapy, his symptoms did not improve. Instead, dyspnea and diffuse bilateral alveolar infiltrates developed and he was referred to our hospital for the management of progressive dyspnea. He had a history of sinusitis at the age of 18 years and asthma during infancy.

On admission, his temperature was $37.9^{\circ} \mathrm{C}$. He had bilateral congestion of the bulbar conjunctivae, bilateral pallor of the palpebral conjunctivae, and inflammation of the nasal cavity. His blood pressure was $112 / 50 \mathrm{mmHg}$ and the pulse rate was $72 /$ $\min$ (regular). Breath sounds were diminished in the right lower lung field and discontinuous sounds were heard at the bilateral bases. Petechiae were presented on the lower legs. There were no abnormal abdominal or neurological findings.

The abnormal laboratory findings were as follows (Table 1): red blood cell count, $2.61 \times 10^{6} / \mathrm{mm}^{3}$; hemoglobin concentration, $6.8 \mathrm{~g} / \mathrm{dl}$; platelet count, $40.4 \times 10^{4 / \mathrm{mm}^{3}}$; total protein, $6.8 \mathrm{~g} /$

From the First Department of Internal Medicine, *the Department of Nephrology and **the Second Department of Pathology, Tokyo Medical College, Tokyo Received for publication September 26, 1996; Accepted for publication March 13, 1997

Reprint requests should be addressed to Dr. Masayuki Kikawada, the First Department of Internal Medicine, Tokyo Medical College, 6-7-1 Nishishinjuku, Shinjuku-ku, Tokyo 160 


\section{Alveolar Hemorrhage Associated with PR3-ANCA}

Table 1. Laboratory Data on Admission

\begin{tabular}{|c|c|c|c|}
\hline \multicolumn{2}{|l|}{ Hematology } & \multicolumn{2}{|c|}{ T-cell subsets (peripheral) } \\
\hline Red blood cell count & $261 \times 10^{4} / \mu \mathrm{l}$ & $\mathrm{CD} 4$ & $38.3 \%$ \\
\hline Hemoglobin & $6.8 \mathrm{~g} / \mathrm{dl}$ & CD8 & $36.9 \%$ \\
\hline Hematocrit & $21.5 \%$ & CD4/8 & 1.04 \\
\hline White blood cell count & $8,600 / \mu \mathrm{l}$ & Legionella antibody & $(-)$ \\
\hline Stab neutrophils & $5.2 \%$ & Mycoplasma (CF) & $(-)$ \\
\hline Segmented neutrophils & $70.0 \%$ & Chlamydia $(\mathrm{CF})$ & $(-)$ \\
\hline Lymphocytes & $14.8 \%$ & & \\
\hline Eosinophils & $5.2 \%$ & \multirow{2}{*}{\multicolumn{2}{|c|}{$\begin{array}{l}\text { Purified protein derivative } \\
\text { skin test }\end{array}$}} \\
\hline Platelets & $40.9 \times 10^{4} / \mu \mathrm{l}$ & & \\
\hline Blood chemistry & & Urinalysis & \\
\hline Aspartate aminotransferase & $66 \mathrm{IU} / l$ & Protein & $(+)$ \\
\hline Alanine aminotransferase & $119 \mathrm{IU} / l$ & Sugar & $(-)$ \\
\hline Total protein & $6.8 \mathrm{~g} / \mathrm{dl}$ & Red blood cell & $100 / \mathrm{F}$ \\
\hline Albumin & $3.2 \mathrm{~g} / \mathrm{dl}$ & Granular casts & $1-2 / \mathrm{F}$ \\
\hline Alkaline phosphatase & $231 \mathrm{IU} / \mathrm{l}$ & & \\
\hline Lactic acid dehydrogenase & $437 \mathrm{IU} / l$ & \multicolumn{2}{|c|}{ Arterial blood gas (room air) } \\
\hline Choline esterase & $0.5 \Delta \mathrm{pH}$ & $\mathrm{pH}$ & 7.464 \\
\hline Total bilirubin & $1.0 \mathrm{mg} / \mathrm{dl}$ & $\mathrm{PaCO}_{2}$ & 40.2 Torr \\
\hline Blood urea nitrogen & $12.4 \mathrm{mg} / \mathrm{dl}$ & $\mathrm{PaO}_{2}$ & 74.0 Torr \\
\hline Creatinine & $0.77 \mathrm{mg} / \mathrm{dl}$ & $\mathrm{HCO}_{3}^{-}$ & $28.8 \mathrm{mEq} / \mathrm{l}$ \\
\hline $\mathrm{Na}$ & $139 \mathrm{mEq} / \mathrm{l}$ & $\mathrm{SaO}_{2}$ & $92.0 \%$ \\
\hline $\mathrm{K}$ & $5.1 \mathrm{mEq} / l$ & & \\
\hline $\mathrm{Cl}$ & $101 \mathrm{mEq} / \mathrm{l}$ & $\begin{array}{l}\text { Bronchoalveolar } \\
\text { lavage fluid (BALF) }\end{array}$ & \\
\hline Erythrocyte sedimentation rate & $135 \mathrm{~mm} / \mathrm{h}$ & $\begin{array}{l}\text { Total cell count } \\
\text { Cell differential }\end{array}$ & $3.5 \times 10^{5} / \mathrm{ml}$ \\
\hline Serology & & macrophages & $51.0 \%$ \\
\hline C-reactive protein & $15.3 \mathrm{mg} / \mathrm{dl}$ & lymphocytes & $6.0 \%$ \\
\hline $\operatorname{IgG}$ & $2,222 \mathrm{mg} / \mathrm{dl}$ & neutrophils & $20.0 \%$ \\
\hline $\operatorname{Ig} \mathrm{A}$ & $144 \mathrm{mg} / \mathrm{dl}$ & eosinophils & $23.0 \%$ \\
\hline $\operatorname{IgM}$ & $83.8 \mathrm{mg} / \mathrm{dl}$ & $\mathrm{CD} 4 / 8$ & 0.54 \\
\hline $\operatorname{IgE}$ & $824 \mathrm{IU} / \mathrm{ml}$ & & \\
\hline Rheumatoid factor & $(-)$ & & \\
\hline Complement 3 & $73 \mathrm{mg} / \mathrm{dl}$ & & \\
\hline Complement 4 & $20 \mathrm{mg} / \mathrm{dl}$ & & \\
\hline $50 \%$ hemolytic unit of complement & $38.7 \mathrm{U} / \mathrm{dl}$ & & \\
\hline Antinuclear antibody & $(-)$ & & \\
\hline Immunocomplex & $(-)$ & & \\
\hline Lupus anti coagulant & $(-)$ & & \\
\hline $\begin{array}{l}\text { Antiglomerular basement } \\
\text { membrane antibody }\end{array}$ & $(-)$ & & \\
\hline $\begin{array}{l}\text { Myeloperoxidase specific anti-neutr } \\
\text { cytoplasmic antibodies }\end{array}$ & rophil & & \\
\hline $\begin{array}{l}\text { Proteinase } 3 \text { specific anti-neutrophil } \\
\text { cytoplasmic antibodies }\end{array}$ & $300 \mathrm{EU}$ & & \\
\hline
\end{tabular}

$\mathrm{PaCO}_{2}$ : partial pressure of carbon dioxide; $\mathrm{PaO}_{2}$ : partial pressure of oxygen, $\mathrm{HCO}_{3}^{-}$: bicarbonate, $\mathrm{SaO}_{2}$ : saturation of oxygen.

$\mathrm{dl}$; aspartate aminotransferase (AST), $66 \mathrm{U} / l$; aranine aminotransferase (ALT), $119 \mathrm{U} /$; ; gamma-glutamyl transpeptidase $(\gamma$-GTP), $108 \mathrm{U} / l$; erythrocyte sedimentation rate, $135 \mathrm{~mm} / \mathrm{h}$; and C-reactive protein, $15.3 \mathrm{mg} / \mathrm{dl}$. No elevation of viral antibody titers was detected. Urinalysis revealed proteinuria, red blood cells, and white blood cells. Arterial blood gases (on room air) were as follows: $\mathrm{PaO}_{2}, 74.0$ Torr; $\mathrm{PaCO}_{2}, 40.2$ Torr; and $\mathrm{pH}, 7.46$. Rheumatoid factor, antinuclear antibody, the lupus erythematosus test, lupus anticoagulant, and immune complexes were all negative. Complement studies $\left[\mathrm{CH} 50, \mathrm{C}_{3}\right.$, and $\mathrm{C}_{4}$ ] gave results within normal limits. Anti-glomerular basement membrane antibody and MPO-ANCA were negative, 

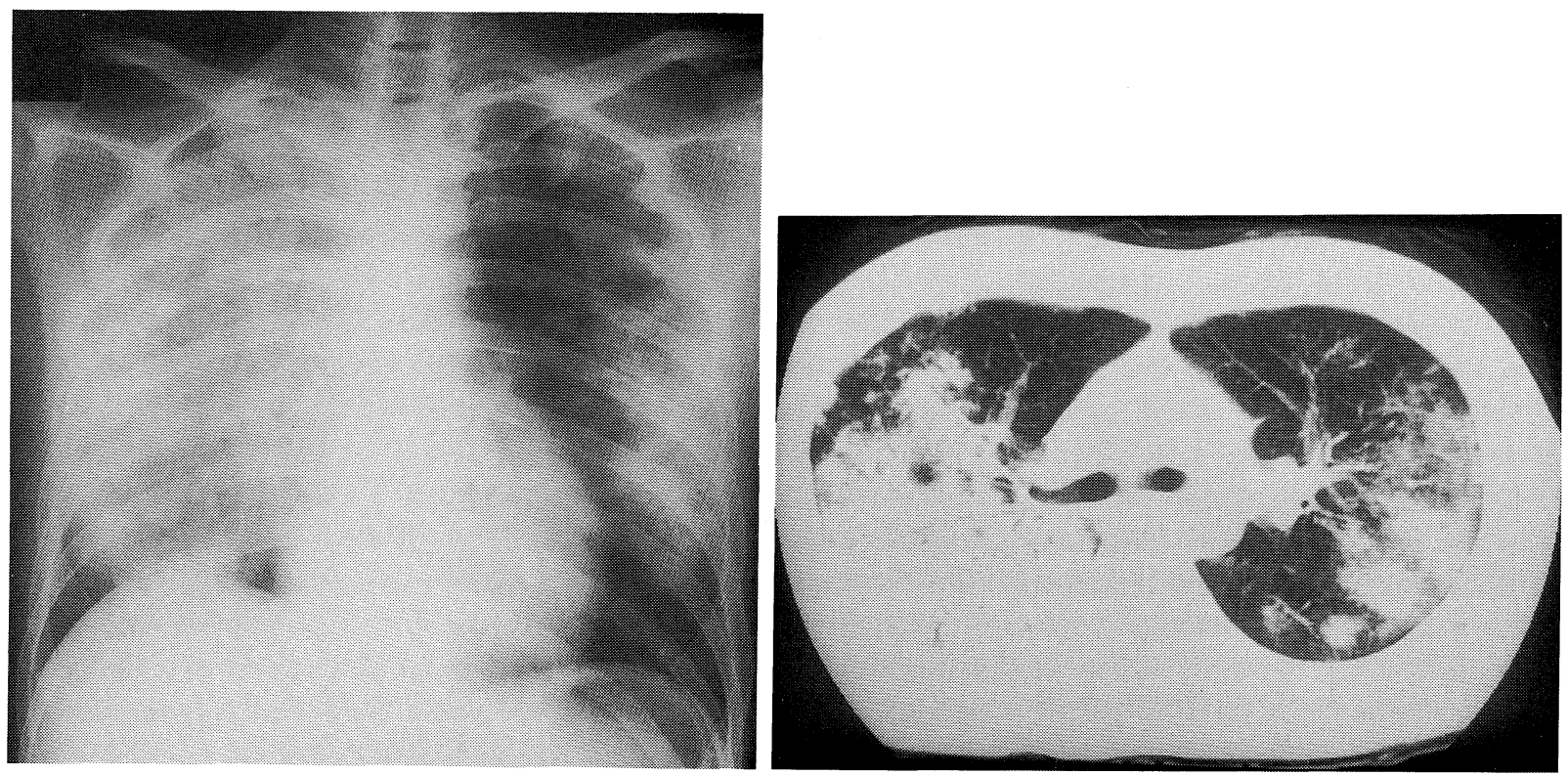

Figure 1. Chest X-ray film and chest CT scan on admission showing alveolar infiltrates.

but PR3-ANCA analyzed by enzyme-linked immunosorbent assay (ELISA: nephroscolor C-ANC, EURO-DIAGNOZTICA $\mathrm{AB}$, Malmo, Sweden) was positive ( $300 \mathrm{EU})$. The chest $\mathrm{X}$-ray film and chest computed tomography (CT) scan showed alveolar infiltrates, especially in the right lung field (Fig. 1). Bronchoscopy revealed bleeding in almost all of the bronchi. Bronchoalveolar lavage (BAL) was performed (right $\mathrm{B}^{4}$ ) and the bronchoalveolar lavage fluid (BALF) was bloody, containing many hemosiderin-laden macrophages. The total cell count of lavage fluid was $3.5 \times 10^{5} / \mathrm{ml}$, with $20 \%$ neutrophils, $23 \%$ eosinophils, and $51 \%$ alveolar macrophages. Elevation of the eosinophil ratio in BALF suggested immune complex disease or systemic vasculitis.

At 6 days after admission, the alveolar infiltrates had diffusely extended to involve the bilateral lung fields on chest X-ray films and many granular casts were detected on urinalysis. Steroid pulse therapy was started on day 5 for respiratory failure and was followed by maintenance therapy with prednisolone $(60$ $\mathrm{mg}$ /day) from March 10. At the same time, renal, skin, and nasal mucosal biopsy, and transbronchial lung biopsy (TBLB) were performed.

The number of glomeruli obtained by renal biopsy was 34 , and histological examination revealed that $50 \%$ of the glomeruli were severely damaged. Crescent formation was detected in $30 \%$ of the observed glomeruli and global sclerosis (often with necrotizing lesions) was seen in the remainder. The interstitium was partially infiltrated with lymphocytes and a few plasma cells, and showed fibrotic changes. Deposits of immunoglobulin $\mathrm{G}$, immunoglobulin $\mathrm{M}, \mathrm{C}_{3}$, and $\mathrm{C}_{4}$ were not detected by immunofluorescence studies. Vasculitis and granulomatous changes also were not detected. The renal findings were consistent with a diagnosis of crescentic glomerulonephritis (Fig. 2).

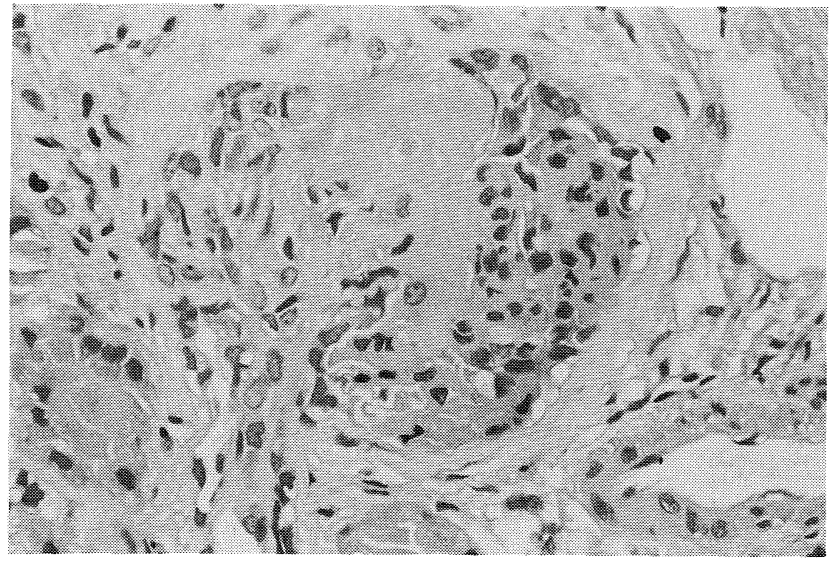

Figure 2. Renal biopsy showing crescentic glomerulonephritis (HE stain, $\times \mathbf{4 0 0}$ ).

Skin biopsy at a site with petechiae showed small vessel leukocytoclastic vasculitis (Fig. 3), while lung biopsy showed a nonspecific intra-alveolar organizing process without granulomas or vasculitis (Fig. 4). Nasal biopsy showed only nonspecific inflammation and no granulomas or vasculitis were observed.

After steroid therapy for two weeks, his symptoms and alveolar infiltrates improved rapidly. However, proteinuria and granular casts were still found on urinalysis. Cyclophosphamide $(100 \mathrm{mg} /$ day) was added to prednisolone on April 1. About one month later, renal biopsy was performed again. The crescents had undergone fibrosis, and there was no active inflammation in the interstitium. In addition, the PR3-ANCA 


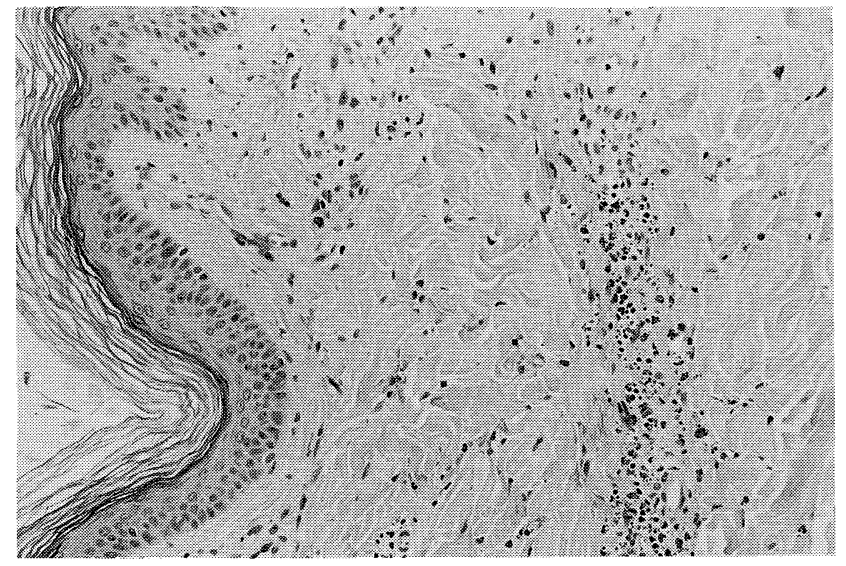

Figure 3. Skin biopsy at a site with petechiae showing small vessel leukocytoclastic vasculitis (HE stain, $\times 100$ ).

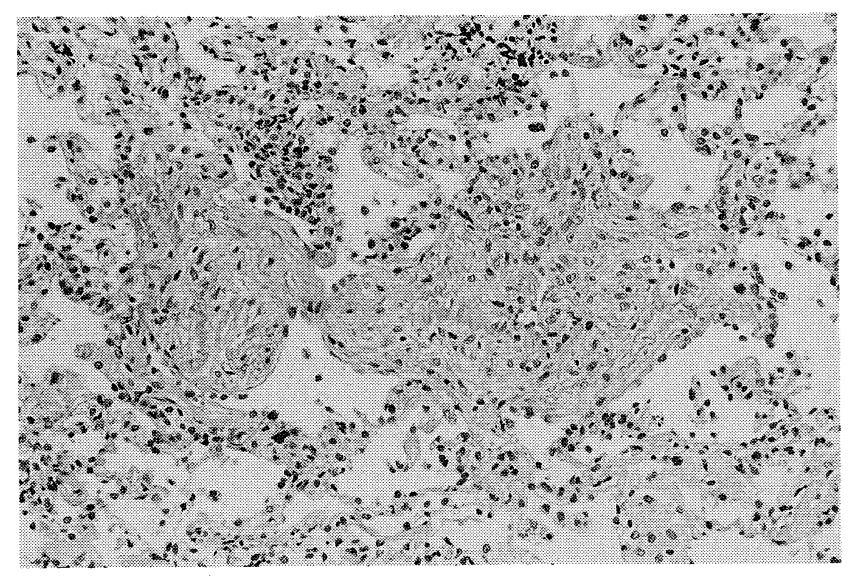

Figure 4. Lung biopsy showing a nonspecific intra-alveolar organizing process without granulomas or vasculitis (HE stain, $\times \mathbf{2 0}$ ).

level fell to within the normal range.

\section{Discussion}

WG is generally characterized by necrotizing granulomatous vasculitis of the upper and lower respiratory tract, the kidneys, and other organs (7). The present patient had alveolar hemorrhage, crescentic glomerulonephritis, skin vasculitis, conjunctival congestion, and nasal inflammation in addition to PR3-ANCA positivity. These findings were highly suggestive of WG, but the final diagnosis must be based on the histological findings obtained by examination of biopsy specimens. No granulomas were found on biopsy and no nodular changes (suggestive of granulomas) were seen on X-ray films or CT scans despite a whole body survey. The leukocytoclastic vasculitis detected by skin biopsy was not enough for a diagnosis of WG. It is of course possible that the small amount of lung tissue obtained or the presence of hemorrhage prevented the detection of granulomas (8), but biopsy material from the skin, upper respiratory tract, or kidney is usually enough to make a final diagnosis. On the other hand, Hoffman et al reported that $8 \%$ of WG patients were not diagnosed correctly for a very long period (5-16 years) (9), thus long-term follow-up of this case is important.

Since Davies et al (10) detected ANCA in a few patients with segmental necrotizing glomerulonephritis in 1982, these antibodies have been reported in many cases of systemic vasculitis. Because PR3-ANCA are frequently recognized in patients with WG (11), these antibodies are generally considered to be a sensitive and specific marker for this disease. It has also been reported that a few WG patients present with pulmonary hemorrhage as the initial manifestation(12-14). The specificity of PR3-ANCA for active WG was initially considered to be more than $90 \%$ (15). However, Kallenberg et al (16) subsequently reported that PR3-ANCA was far from specific for WG and there have been some cases of non-WG vasculitis with PR3-ANCA positivity.

Most systemic vasculitides are not wellknown or completely understood with regard to etiology and pathogenesis, so their classification is based on a combination of clinical and pathological findings. The nomenclature and classification of systemic vasculitis that is universally acceptable has not been established yet. The American College of Rheumatology (ACR) described criteria for the classification of vasculitis in 1990 (17), and concluded that criteria based on clinical findings which identify the disease and distinguish it from others are not appropriate to use in the diagnosis of individual patient. The Chapel Hill Consensus Conference attempted to classify systemic vasculitis based on the affected vessels (18). The conference also defined a new disease, termed as microscopic polyangiitis, in which necrotizing small vessel vasculitis affects the arterioles, venules, and capillaries. Since it may be difficult to differentiate whether an ANCA-associated pulmonaryrenal vasculitic syndrome is caused by WG or microscopic polyangiitis due to the overlapping features of these diseases, the diagnostic terms used for vasculitis will change over time in some patients. The present case is considered to be suggestive of WG or microscopic polyangiitis with respiratory tract involvement according to the Chapel Hill Consensus Conference criteria, and may most likely be WG due to the lack of necrotizing small vessel vasculitis in the arterioles, in addition to positivity for PR3-ANCA. However, since Lie has doubt for a definitive term of "microscopic polyangiitis" as a clinicopathologic entity (19), it is expected that more precise criteria for classifying systemic vasculitis will be established.

Since combined therapy with steroids and cyclophosphamide was introduced, the prognosis of vasculitis has improved markedly (20). It is important to start treatment as soon as possible before irreversible organ damage occurs. If the treatment of alveolar hemorrhage is delayed or not performed, the patient's condition will become progressively worse. In some cases, a diagnosis of vasculitis is only made at autopsy (21). At present, ANCA provides useful information for the early diag- 
nosis and treatment of pulmonary-renal vasculitic syndrome.

In summary, we have described a PR3-ANCA-positive patient whose initial manifestations were diffuse alveolar hemorrhage and crescentic glomerulonephritis. He showed a good response to combination therapy with steroids and cyclophosphamide.

\section{References}

1) Goodpasture EW. The significance of certain pulmonary lesions in relation to the etiology of influenza. Am J Med Sci 158: 863, 1919.

2) Osler W. On the visceral manifestations of the erythema group of skin diseases. Am J Med Sci 127: 1, 1904.

3) Albelda SM, Gefter WB, Epstein DM, Miller WT. Diffuse pulmonary hemorrhage: A review and classification. Radiology 154: 289, 1985.

4) Arimura $Y$, Minoshima S, Tanaka U, et al. Pulmonary involvement in patients with myeloperoxidase specific-antineutrophil cytoplasmic antibody. Ryumachi 35: 46, 1995 (Abstract in English).

5) Falk RJ, Jennette JC. Anti-neutrophil cytoplasmic autoantibodies with specificity for myeloperoxidase in patients with systemic vasculitis and idiopathic necrotizing and crescentic glomerulonephritis. N Engl J Med 318: $1651,1988$.

6) Ludemann J, Utecht B, Gross WL. Anti-neutrophil cytoplasm antibodies in Wegener's granulomatosis recognize an elastinolytic enzyme. J Exp Med 171: 357, 1990.

7) Fauci AS, Wolff SM. Wegener's granulomatosis: Studies in eighteen patients and a review of the literature. Medicine (Baltimore) 52: 535, 1973.

8) Cordier JF, Valeyre D, Guillevin L, Loire R, Brechot JM. Pulmonary Wegener's granulomatosis. A clinical and imaging study of 77 cases. Chest 97: 906, 1990.

9) Hoffman GS, Kerr GS, Leavitt RY, et al. Wegener granulomatosis: An analysis of 158 patients. Ann Intern Med 116: 488, 1992 (see comments).
10) Davies DJ, Moran JE, Niall JF, Ryan GB. Segmental necrotizing glomerulonephritis with antineutrophil antibody: possible arbovirus aetiology? Br Med J (Clin Res Ed) 285: 606, 1982.

11) van der Woude FJ, Rasmussen N, Lobatto $S$, et al. Autoantibodies against neutrophils and monocytes: Tool for diagnosis and marker of disease activity in Wegener's granulomatosis. Lancet 1: 425, 1985.

12) Hensley MJ, Feldman NT, Lazarus JM, Galvanek EG. Diffuse pulmonary hemorrhage and rapidly progressive renal failure. An uncommon presentation of Wegener's granulomatosis. Am J Med 66: 894, 1979.

13) Myers JL, Katzenstein AL. Wegener's granulomatosis presenting with massive pulmonary hemorrhage and capillaritis. Am J Surg Pathol 11: 895, 1987.

14) Colby TV. Diffuse pulmonary hemorrhage in Wegener's granulomatosis. Semin Respir Med 10: 136, 1989.

15) Specks U, Wheatley CL, McDonald TJ, Rohrbach MS, DeRemee RA. Anticytoplasmic autoantibodies in the diagnosis and follow-up of Wegener's granulomatosis. Mayo Clin Proc 64: 28, 1989.

16) Kallenberg CG, Brouwer E, Weening JJ, Tervaert JW. Anti-neutrophil cytoplasmic antibodies: Current diagnostic and pathophysiological potential. Kidney Int 46: 1, 1994.

17) Hunder GG, Arend WP, Bloch DA, et al. The American College of Rheumatology 1990 criteria for the classification of vasculitis: Introduction. Arthritis Rheum 33: 1065, 1990.

18) Jennette JC, Falk RJ, Andrassy K, et al. Nomenclature of systemic vasculitides: Proposal of an international consensus conference. Arthritis Rheum 37: 187, 1994.

19) Lie JT. Nomenclature and classification of vasculitis: Plus ca change, plus c'est la meme chose. Arthritis Rheum 37: 181, 1994 (editorial).

20) Fauci AS, Haynes BF, Katz P, Wolff SM. Wegener's granulomatosis: Prospective clinical and therapeutic experience with 85 patients for 21 years. Ann Intern Med 98: 76, 1983.

21) Travis WD, Carpenter HA, Lie JT. Diffuse pulmonary hemorrhage: An uncommon manifestation of Wegener's granulomatosis. Am J Surg Pathol 11: 702, 1987. 